\title{
Особенности интернационализации ритейла в Украине
}

\author{
Галина П. Штапаук
}

\begin{abstract}
Streszczenie: Specyfika rozwoju handlu detalicznego na Ukrainie, poprzez jego dalszą internacjonalizację, polega na zaspokajaniu różnorodnych potrzeb konsumentów, co zmusza detalistów do dywersyfikacji swoich możliwości, przy jednoczesnym uwzględnieniu specjalistycznych potrzeb poszczególnych grup klientów. W wyniku połączenia dwóch przeciwstawnych trendów - dywersyfikacji i specjalizacji na rynku konsumenckim - kształtuje się nowa dualistyczna strategia, która dyktuje logikę powstawania i rozwoju nowych formatów handlowych przedsiębiorstw. Badania i synteza nowych trendów w rozwoju tych formatów handlu światowego stają się warunkiem wstępnym określenia przez przedsiębiorców własnej strategii utrzymywania pozycji na rynku konsumenckim.
\end{abstract}

Słowa kluczowe: rynek, konsument, potrzeby, internacjonalizacja, strategia.

\section{1. Введение}

Сдвиги на потребительском рынке Украины, происходящие под влиянием изменения уровня материального состояния и покупательной способности потребителей, являются самыми влиятельными факторами развития системы розничной торговли (ритейла), которая все больше опирается на мировой опыт и постепенно интернационализируется. Все больше торговые предприятия в Украине, согласно мировой тенденции, вынуждены приспосабливаться к разнообразным потребностям потребителей, как относительно структуры предложения товаров и услуг для населения, так и по выбору форм осуществления торговой деятельности.

* Луганский национальный университет имени Тараса Шевченко, к.э.н., доц. кафедры экономической теории, маркетингу и предпринимательства, г. Старобельск. 
Развитие ритейла в любой стране тесно связано со структурой расходов населения, которая косвенно отражает уровень социального благополучия - считается, что чем больше доля расходов на еду, тем беднее является государство. По статистическим данным среднестатистический житель Украины тратит на питание более 53\% своих доходов, что не сопоставимо с аналогичными данными других стран: в Соединенных Штатах население в среднем тратит на еду $6,8 \%$ своих доходов, в Ирландии - 7,2\%, в ОАЭ $-8,7 \%$, в Великобритании $-8,8 \%$, в Канаде $-9,1 \%$. В Евросоюзе на еду тратят в среднем $16 \%$ доходов.

Структура расходов потребителей в Украине в течение длительного времени формировала определенную структуру предприятий торговли, которые имели различные торговые форматы: от супермаркетов до небольших магазинов на городских рынках. Но созданная годами структура предприятий торговли в последнее время подвергается значительной деформации под влиянием новейших тенденций, происходящих на потребительском рынке.

\section{2. Развитие структуры потребительского рынка}

Определяют следующие тенденции сдвигов на потребительском рынке Украины:

- во-первых, основное направление преобразований происходит под влиянием ежегодного роста объемов розничного товарооборота, который за последние 10 лет увеличился почти в 10 раз;

- во-вторых, процесс развития украинского розничного рынка происходит с широким использованием мирового опыта развития торговли и вхождением в Украину известных мировых торговых фирм;

- в-третьих, неопределенность многих проявлений быстро меняющейся структуры потребительского спроса и отсутствие реальных механизмов их учета не предоставляют возможностей коммерческим предприятиям осуществлять обоснованный выбор решения относительно формата своей деятельности из множества форм и методов современной торговли, из-за чего значительное количество торговых предприятий не выдерживают конкуренции, часто меняют свой профиль и нередко прекращают деятельность.

На фоне указанных особенностей процесс ускорения проникновения на украинский рынок новейших мировых товаров неизбежно стимулировал структурные сдвиги в самой торговой сфере и вхождения на рынок розничной торговли мировых торговых брендов. Так, согласно мировой тенденции, 
в Украине происходит постепенное увеличение концентрации в коммерческой сфере, отражающая тенденция снижения общего количества торговых предприятий при увеличении среднего объема товарооборота одним предприятием. В течение последних 10 лет количество предприятий розничной торговли, которое составляло примерно 121 тысяч субъектов, в настоящее время уменьшилось почти на 40\%. При этом в большей степени сократилось количество магазинов - более чем на $44 \%$, в то время как количество мелких торговых точек (киосков и палаток) уменьшилась на 26,6\%. Соответственно, в 10-15 раз увеличился средний товарооборот одного торгового объекта.

В целом в Украине происходит свой неповторимый путь развития потребительского рынка в Украине, который ставит перед торговыми предприятиями новые задачи по обеспечению их устойчивости в новых условиях. Торговые предприятия, как более мобильные в части изменения своего профиля по сравнению с производственными, вынуждены вырабатывать собственную стратегию поддержания устойчивости, которая варьирует между диверсификацией, что означает максимальное расширение торгового ассортимента на единой материальной базе, и специализацией, которая, наоборот, нацеливает предприятие на узкий сегмент потребительского рынка.

В результате отмеченных процессов происходит постоянное сокращение количества «унитарных» предприятий и увеличение форматов торговых объектов с явным проявлением диверсификации: таких, как, например, ООО «Метро кэш энд керри Украина», входящая в состав немецкого холдинга «Metro Group», компания «Билла Украина», входящая в концерн REWE Group, 3AO «Фуршет», частью акций которого владеет французская сеть гипермаркетов «Auchan» и др.

Наряду с мировыми фирмами, которые работают в Украине, отмечается значительный рост региональных торговых компаний (например, ООО «Омега», которое владеет сетью «Варус», сеть фрешмарктов «Брусничка», сеть удобно расположенных магазинов «Апельмон» формата «у дома», ориентированных на быстрое приобретение качественных товаров в г. Запорожье и др.). Но этот процесс не отражающим единственное направление развития торговых сетей, как и раньше, ведущую роль играют торговые предприятия меньшего размера с традиционным подходом к формированию своего ассортимента и организации торговых процессов на основе специализации. Поэтому диверсификация и специализация становятся составляющими стратегии поддержания устойчивости торговых предприятий в Украине. Понятно, что и процесс интернационализации торговых сетей в Украине не может выйти из под влияния этих обстоятельств.

Вторым важнейшим фактором интернационализации розничной торговли является состояние развития потребительского общества, которое в очень значительной степени зависит от общих социально-экономических трендов целой страны, а именно, от: 
- снижения жизненных стандартов из-за уменьшения курса национальной валюты;

- роста цен на потребительские товары в результате инфляции;

- сокращения потребительского кредитования;

- повышения ввозных пошлин;

- увеличения уровня безработицы;

- ухудшения из-за более жесткой регламентации налогового обложения деятельности малого бизнеса, субъекты которого составляют значительную часть потребителей различных товаров и услуг;

- ограничения в сфере прямых денежных выплат широким слоям пенсионеров и лиц, которые получат различные формы социальной помощи и т.д.

\section{3. Направления интернационализации ритейла}

Вследствие таких изменений даже самые крупные и успешные торговые брендовые фирмы стоят перед неясностью определения стратегии ближайшего развития. Так, в вопросе развития в Украине деятельности фирмы «Билла-Украина» пока не озвучивается количество запланированных к открытию магазинов, которых сначала было около 30, а в дальнейшем их количество значительно сократилось. С трудом принимается решение о вхождении на рынок Украины международной торговой сети «ИКЕА».

В целом, благодаря интернационализации всех направлений развития розничной торговли в Украине расширяется спектр применения различных форматов торговых предприятий при отсутствии надежных критериев лучшего выбора из числа следующих форм:

- розничные магазины, универмаги, супермаркеты, гипермаркеты, выставочные залы, магазины клубы, специализированные магазины, дискаунтные магазины и др.;

- различные виды безмагазинной торговли (прямой маркетинг, продажи «один на один», продажа «один многим» и др., в форме торговли по телефону, с помощью телевизора, по почте - «директ-мейл», с помощью визитов торговых агентов, через сеть ИНТЕРНЕТ и другие информационные компьютерные системы).

В общем, из-за поиска предприятиями наиболее устойчивых к условиям меняющегося рынка торговых форматов структура предприятий розничной торговли находится в постоянном изменении, поскольку постоянно появляются новые виды торговых предприятий. Но при этом практически не подлежит прямому копированию ни одна из версий развития торговой роз- 
ничной сети, принятых в странах Америки или Европы, в частности, американская система, при которой примерно 75\% составляют средние и крупные предприятия, использующие наемный труд, и примерно около 25\% - мелкие и мелкие розничные предприятия, не использующие наемный труд.

Поскольку развитие торговой сети происходит путем инвестирования и дальнейшей концентрации капитала и увеличение размеров торговых предприятий, развитие вертикальной интеграции является незыблемым принципом и для Украины. Актуальными становятся цепные компании, во главе которых находится центральная закупочная контора, а на нижнем уровне - розничные предприятия (цепная компания), или объединение розничных фирм, которые приобретают товары в оптовой фирме (добровольная цепь) или кооперативные объединения розничных предприятий и оптовой фирмы во владении одного владельца, как это отражено на рисунке 1.

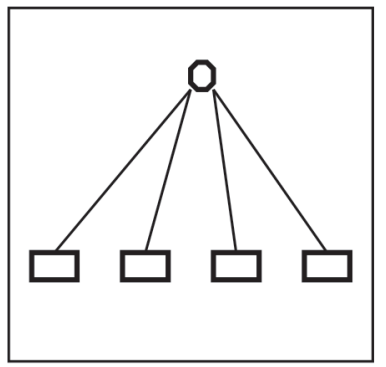

a

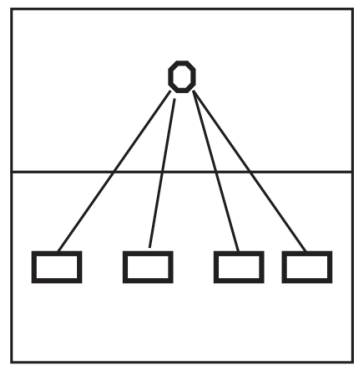

б

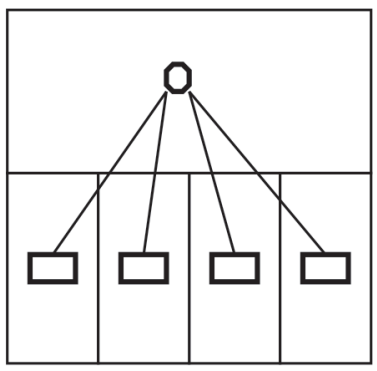

B

Рисунок 1. Три основные формы вертикальной интеграции в розничной торговле Украины (вертикальные и горизонтальные разделительные линии отображают границы собственности): а - цепная компания; б - добровольная цепь; в - кооперативные объединения

Согласно представленной схемы в роли оптового участника торговой сети могут выступать:

1) оптовые фирмы, которые покупают, хранят и продают товары розничным торговцам, предприятиям сферы услуг, промышленным компаниям и др. (дистрибьюторы);

2) торговые посредники (брокеры, агенты), которые, как правило, не приобретают прав собственности на товар, осуществляя операции по его хранению и организации снабженческих соглашений;

3) сбытовые конторы промышленных компаний, обособленные в организационном отношении от производственных подразделений.

Альтернативным направлением остается соединение оптового и розничного переделов торговли в форме мелкооптовых магазинов-складов типа «кэш энд керри», типичным представителем которых в Украине является компания «МЕТРО Кэш энд керри Украина». 
Особенности стратегии «МЕТРО Кэш энд керри Украина» стал переход фирмы к сокращенному формату деятельности «METRO баз», первые предприятия которого открыты в Украине. Основные отличия нового формата предприятия «METRO баз» от базового в том, что они отражают существенные сдвиги в покупательском спросе, продемонстрированные данными таблицы 1.

Таблица 1. Особенности форматов торговых предприятий фирмы МЕTРО в Украине

\begin{tabular}{|c|c|c|}
\hline \multirow{2}{*}{ Характеристика } & \multicolumn{2}{|c|}{ Формат торгового объекта } \\
\hline & METRO Cash \& Carry & METRO баз \\
\hline Общая площадь & До 16000 кв. м & До 2000 кв. м \\
\hline Ассортимент & $\begin{array}{l}30000 \text { наименований } \\
\text { продовольственных } \\
\text { и непродовольственных товаров }\end{array}$ & $\begin{array}{l}3 \text { о00 наименований } \\
\text { преимущественно } \\
\text { продовольственных } \\
\text { товаров }\end{array}$ \\
\hline Клиенты & \multicolumn{2}{|c|}{$\begin{array}{l}\text { Представители сегмента HoReCa, розничной торговли, офисов } \\
\text { и компаний, а также покупатели, которые удовлетворяют } \\
\text { собственные потребности }\end{array}$} \\
\hline Поставщики & \multicolumn{2}{|c|}{$\begin{array}{l}\text { Более 90\% продукции закупается у украинских производителей, } \\
\text { дистрибьютеров и импортеров }\end{array}$} \\
\hline Помещения & Собственные & Арендованные \\
\hline
\end{tabular}

Как свидетельствуют данные об ассортименте нового формата «METRO баз» его появление стало следствием нового проявления специализации, что вылилось в уменьшение общей торговой номенклатуры в 10 раз.

Об этом свидетельствуют данные о довольно разном уровне цен на одни и те же товары в магазинах, отличающихся размерами и объемом товарооборота, а также о значительной разнице цен на одни и те же товары в обычных и статусных торговых заведениях. В проводимых нами исследованиях сопоставлялись цены на некоторые товары - продукты ежедневного потребления и деликатесы в магазинах следующих типов:

- статусный - статус торгового учреждения заведения типа «SPAR» (gourmet) со значительной торговой площадью и объемом товарооборота с деликатесным набором продуктов;

- продуктовый магазин, гастроном с торговой площадью до 100-200 кв. м и товарооборотом 100-150 тыс. грн. ежедневно со стандартным ассортиментом товаров;

- супермаркет площадью от 0,5 до 1,5 тыс. кв. м и ежедневным товарооборотом в 400-700 тыс. грн. с полным набором продуктов и сопутствующих товаров (типа «Фуршет»); 
- дискаунтер типа «Кэш энд кэрри», площадью более 4 тыс. кв. м с ежедневным товарооборотом свыше 1000 тыс. грн., или среднего размера (например, система заведений «АТБ») с максимально широкой номенклатурой товаров, продаваемых по оптовым ценам, или по ценам, приближенным к ним;

- торговая палатка, рыночный прилавок, магазин на рынке - субъект частного предпринимательства, специализированный на определенных группах товаров со значительным объемом продаж по отдельным товарным позициям.

В таблицы 2 приведены результаты исследования в виде индикативных цен на одни и те же товары, при этом за 1 приняты цены, характерные для обычных для Украины магазинов типа «гастроном».

В результате исследования установлено, что имеет место зависимость цен от размера торгового заведения: самые высокие цены (кроме статусных заведений, приведенных в столбце 2) наблюдаем в магазинах меньшего размера (столбец 3) и, наоборот, в дискаунтерах с наибольшим товарооборотом (столбец 5) цены ниже. Самые низкие цены в торговых палатках или магазинах на рынке можно объяснить значительным объемом продажи отдельных товарных позиций массового потребления.

Таблица 2. Индикативные цены товаров в торговых заведениях разных типов

\begin{tabular}{|c|c|c|c|c|c|}
\hline \multirow{2}{*}{$\begin{array}{c}\text { No } \\
\text { товара }\end{array}$} & \multicolumn{5}{|c|}{ Индикативные цены товаров по торговым заведениям разных типов } \\
\cline { 2 - 6 } & $\begin{array}{c}\text { и объемов товарооборота } \\
\text { статусный }\end{array}$ & $\begin{array}{c}\text { гастроном } \\
\text { с минималь- } \\
\text { ным товаро- } \\
\text { оборотом }\end{array}$ & $\begin{array}{c}\text { супермаркет } \\
\text { со средним } \\
\text { товарооборо- } \\
\text { том }\end{array}$ & $\begin{array}{c}\text { дискаунтер } \\
\text { с максималь- } \\
\text { ным товаро- } \\
\text { оборотом }\end{array}$ & $\begin{array}{c}\text { палатка } \\
\text { с минималь- } \\
\text { ным товаро- } \\
\text { оборотом }\end{array}$ \\
\hline 1 & 1,09 & 1,0 & 0,98 & 0,95 & 0,85 \\
\hline 2 & 1,35 & 1,0 & 0,95 & 0,91 & 0,80 \\
\hline 3 & 1,09 & 1,0 & 0,95 & 0,90 & 0,77 \\
\hline 4 & 1,17 & 1,0 & 0,94 & 0,88 & 0,72 \\
\hline 5 & 1,22 & 1,0 & 0,85 & 0,80 & - \\
\hline 6 & 1,14 & 1,0 & 0,95 & 0,83 & - \\
\hline 7 & 1,24 & 1,0 & 0,92 & 0,84 & 0,71 \\
\hline 8 & 1,28 & 1,0 & 0,92 & 0,87 & 0,70 \\
\hline 9 & 1,18 & 1,0 & 0,87 & 0,80 & - \\
\hline В & 1,20 & 1,0 & 0,92 & 0,86 & 0,78 \\
\hline среднем & 1,20 & & & & \\
\hline
\end{tabular}




\title{
4. Выводы
}

Итак, особенностями развития ритейла в Украине путем его дальнейшей интернационализации является опора на разнообразие потребностей потребителей, что заставляет торговые предприятия диверсифицировать свои возможности, одновременно учитывая специализированные потребности отдельных групп покупателей. В результате сочетания двух противоположных тенденций - диверсификации и специализации на потребительском рынке складывается новая дуалистическая стратегия, которая диктует логику появления и развития новых торговых форматов предприятий. Исследование и обобщение новых тенденций развития мировых форматов торговой деятельности становится необходимым условием определения торговыми предприятиями собственной стратегии удержания своих позиций на потребительском рынке.

\section{Библиография}

Колосов А. М., Колосова К. А., Штапаук Г. П., Управління стійкістю підприємства, Видавництво державного закладу «Луганський національний університет імені Тараса Шевченка», Старобільськ 2016.

\section{Features of the internationalization of retail in Ukraine}

\begin{abstract}
The specifics of development of retail trade in Ukraine, through its further internationalization, consists in satisfying various consumer needs, which forces retailers to diversify their capabilities, while taking into account the specialized needs of individual customer groups. As a result of combining two opposing trends - diversification and specialization on the consumer market - a new dualistic strategy is being developed that dictates the logic of the emergence and development of new commercial formats of enterprises. Research and the synthesis of new trends in the development of these global trade formats are becoming a precondition for entrepreneurs to define their own strategy to maintain their position in the consumer market.
\end{abstract}

Keywords: market, consumer, needs, internationalization, strategy. 